\section{NOVA TELLVS}

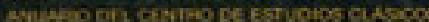

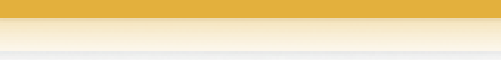

BEUCHOT, Mauricio

Retórica y hermenéutica en Aristóteles

Nova Tellus, vol. 25, núm. 1, 2007, pp. 217-234

Centro de Estudios Clásicos

Distrito Federal, México

Disponible en: http://www.redalyc.org/articulo.oa?id=59120922006

- Cómo citar el artículo

- Número completo

- Más información del artículo

- Página de la revista en redalyc.org

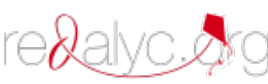

Sistema de Información Científica

Red de Revistas Científicas de América Latina, el Caribe, España y Portugal

Proyecto académico sin fines de lucro, desarrollado bajo la iniciativa de acceso abierto 


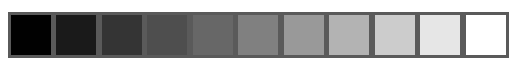

Retórica y hermenéutica en Aristóteles

\author{
Mauricio BeUCHOT \\ Universidad Nacional Autónoma de México \\ hardie@servidor.unam.mx
}

RESUMEN: En este artículo se intentan entresacar las principales ideas de Aristóteles sobre la hemenéutica. Es verdad que algunas de ellas pueden hallarse en el $D e$ interpretatione, pero otras se encuentran en la Retórica. Por eso se trata la hermenéutica aristotélica en conexión con su arte retórica. En ella se cumple la idea de que aquello que sirve para encodificar sirve también para decodificar; y, así como la retórica enseña a hablar y a escribir, también enseña a leer o a interpretar. De manera muy clara puede ejemplificarse esto con la teoría de los tropos, señaladamente la metáfora y la metonimia, que son enseñados por la retóricopoética, y sin menoscabo de la hermenéutica.

$$
* * *
$$

ABstRact: This article focuses on the main ideas developed by Aristotle on hermeneutics. Some of them are to be found in the De interpretatione, whereas the rest appear in the Rhetorica: therefore, the author studies Aristotle's hermeneutics against the background of his own rhetoric. In fact, according to Aristotle, encoding and decoding arise from the use of the same tool, and so rhetoric teaches not only how to speak and write, but teaches also how to read and interpret. This may be clearly exemplified through the theory of topoi, especially metaphor and metonymy, that are studied by rhetoric as well as by poetics, without prejudice to their being considered also by hermeneutics.

PALABRAS ClAVE: Aristóteles, elocución, hermenéutica, interpretación, metáfora, metonimia, retórica.

RECEPCIÓN: 20 de febrero de 2007.

ACEPTACIÓN: 3 de mayo de 2007. 


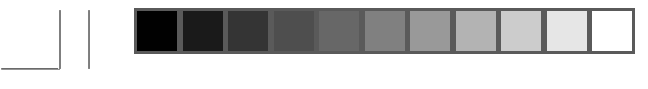

$\oplus$

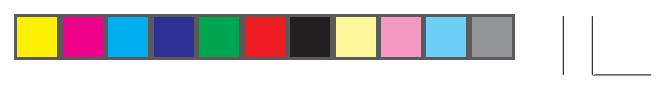

( 

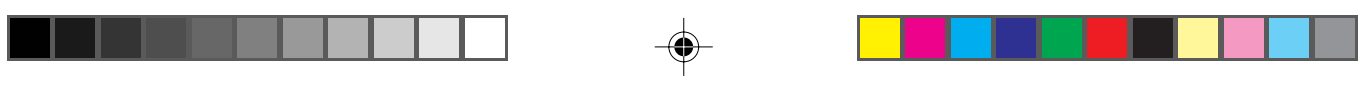

\title{
Retórica y hermenéutica en Aristóteles
}

\author{
Mauricio BEUCHOT
}

\section{Introducción}

En el artículo que sigue atenderé algunas ideas hermenéuticas de Aristóteles. Suele decirse que abordó este tema en el Peri hermeneias, traducido al latín como De interpretatione, y al castellano como De la interpretación; pero tal vez tiene más elementos hermenéuticos en su Retórica, pues en ella se encuentra una teoría de los tropos, y éstos sirven tanto para encodificar un discurso o texto como para decodificarlo. También hay elementos en otros trabajos suyos, como la teoría de la analogía, que se encuentra en la Metafísica y en la Poética Aquí me centraré en la hermenéutica y la analogía aristotélicas, o, si se prefiere, en la analogía dentro de la hermenéutica aristotélica.

Y es que en la Retórica se abarcaba tanto la emisión como la recepción de mensajes, esto es, el circuito comunicativo completo, mientras que hoy en día la hermenéutica se toma sólo como el recibir o decodificar. ¿Cómo leer? Esta parece ser la pregunta fundamental en ella. Veremos que Aristóteles, aunque no tiene propiamente una teoría explícita de la lectura y de la interpretación, nos brinda, sin embargo, datos muy precisos sobre ella en su teoría retórica y en su doctrina de la analogía. 


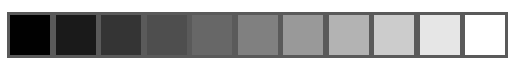

220

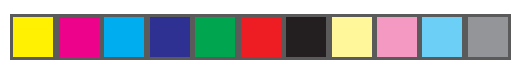

BEUCHOT / Noua tellus, 25•1, 2007, pp. 217-234

\section{La retórica como hermenéutica}

Antes de que Heidegger pusiera la interpretación como una propiedad existencial (un existenciario) del hombre, ${ }^{1}$ Aristóteles veía al ser humano como un animal racional, como teniendo lógos, razón y lenguaje, como un animal comprensor, que en su ubicarse en el mundo lo hace interpretando y comprendiendo. ${ }^{2}$ Además de definir al hombre como animal que tiene lógos (razón-palabra), lo define como animal político, y es precisamente por el lógos por lo que es tal, y no meramente un animal gregario. ${ }^{3}$ La razón se manifiesta en el lenguaje: la lingüisticidad expresa la razón. Por tal motivo el hombre necesita la retórica, piensa el estagirita, porque ella da el acto lingüístico por excelencia, que es el del juicio, al que se llega por un raciocinio o al que se apoya con un argumento. Y la retórica, tal como la entiende Aristóteles, es una argumentación que va a todo el hombre, razón y pasión. Por eso su obra sobre retórica es tanto una lógica (del entimema o silogismo abreviado y rápido) como una psicología de las pasiones (la psicagogía o movimiento pasional), es decir, alude al hombre completo: razón y pasión.

La pragmática y la hermenéutica coinciden en estudiar el significado no en abstracto, sino como significado del hablante, o intencionalidad del emisor, y esto es precisamente lo que enseña la retórica, pues toma muy en cuenta a quién va dirigido el mensaje (i. e., los oyentes o receptores) y, del mismo modo, de quién nos viene el mensaje, esto es, las características peculiares del hablante o del autor de un texto. A diferencia de la sintaxis y la semántica, la pragmática toma muy

\footnotetext{
${ }^{1}$ M. Heidegger, El ser y el tiempo, § 32, México, FCE, 1957, pp. 166 ss.

${ }^{2}$ Pol., I, 2, 1253a 9-10 (en Opera, ed. de I. Bekker, rev. de O. Gigon, Berlin, Walter de Gruyter, 1961).

${ }^{3}$ Pol., I, 2, 1253a 3.
} 

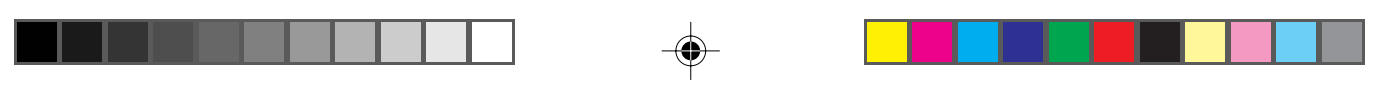

RETÓRICA Y HERMENÉUTICA / Noua tellus, 25•1, 2007, pp. 217-234

en cuenta a los usuarios y lo mismo hace la hermenéutica: atiende al autor y al lector, o emisor y receptor, hablante y oyente. Si es para dirigir el mensaje, hay que atender a las características del auditorio, de los oyentes, del público, o sencillamente del que escucha; y, si es para descifrar un mensaje, hay que atender a las características peculiares del que lo emite: su lenguaje, su cultura, su historia, etcétera. Por eso la retórica tenía que ver tan directamente con la praxis (la ética, la política, la vida cotidiana). Era útil sobre todo para llevar a la acción.

Era lógico, pues, que la retórica estuviera asociada a la ética y a la política, con el fin de buscar lo que es bueno para el hombre y la sociedad, lo que les es útil o deleitable u honesto. En especial, tiene que dirigirse hacia el bien común. Según la teoría aristotélica de la acción, en la que el hombre busca el bien, la retórica sirve para convencer a los otros de que se tiene que buscar lo que resulta benéfico para la polis: procurar un pacto, iniciar una guerra, castigar a algunos, perdonar a otros, o premiarlos o alabarlos, etcétera. Sobre todo, ayudaba a hacer justicia. ${ }^{4}$ Pero esto requiere que se dirija el discurso no sólo a la razón, sino también a la emoción: va al entendimiento y a la voluntad, al hombre íntegro. Es lo que logrará la persuasión o convencimiento.

Aristóteles habla de una técnica retórica, un arte oratoria. ${ }^{5}$ No excluye que se dé a veces una habilidad natural para la retórica, pues hay oradores natos; pero explica que la situación normal es que se aprenda mediante el arte o técnica, y aún el que la tiene de manera natural puede mejorarla con el estudio. Es arte o técnica porque proporciona reglas para guiar y apoyar esa capacidad retórica o (parodiando a Chomsky) compe-

\footnotetext{
${ }^{4}$ Rhet., I, 1, 1354a 18-1355a 2.

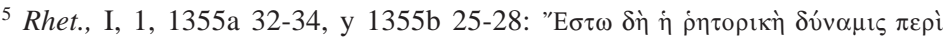

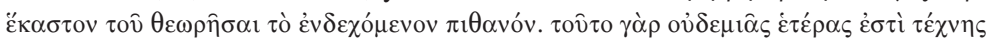

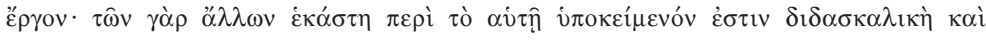

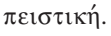




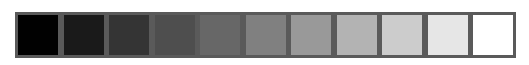

222

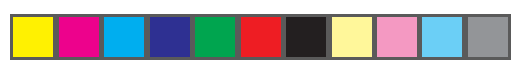

BEUCHOT / Noua tellus, 25•1, 2007, pp. 217-234

tencia retórica que todos tenemos, pero que, si no cultivamos, brillará por su ausencia.

Los sofistas habían hecho de la retórica una erística, un arte de la disputa, y usaban falacias. Servía para demostrar una cosa y su contraria, llegando al absurdo. Gorgias, en quien confluía la tradición, desde Protágoras hasta Isócrates, hacía

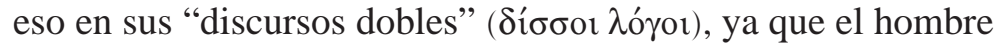
era la medida de las cosas. Tenía la retórica como mero instrumento de poder, no le importaba la verdad. ${ }^{6}$

Sócrates y Platón habían reaccionado contra ese empleo de la retórica, viendo a los sofistas como una amenaza para la polis, pues el arte de la persuasión estaba al servicio de su relativismo moral. Por eso Platón supeditaba la retórica a la ética, como obligando a buscar el bien, concretamente el bien común, y no cualquier interés. Había que conocer el ser, para llegar al deber ser, y eso lo hacía el filósofo o dialéctico. Y tenía que conocer la verdad para reconocer lo verosímil, que significa lo semejante a la verdad, propio de la retórica, como se dice en el diálogo platónico Fedro (273d). Y el filósofo puede hacerlo porque conoce el alma y sus afecciones. ${ }^{7}$

Este ideal platónico es recogido por Aristóteles, que concibe la retórica como referida al intelecto y al afecto. Es una teoría de la argumentación (hacia el intelecto) y una psicología aplicada al movimiento de las pasiones y emociones (hacia la voluntad o afecto). En ella subyace una filosofía del hombre o antropología filosófica, para la cual éste es libre, dialógico y puede ser persuadido no sólo por el intelecto, sino también por el afecto, y han de estudiarse los mecanismos de la persuasión. Esto se da en el diálogo, que tiene su retórica, su deliberación. Y es constitutivo de la hermenéutica. El diá-

\footnotetext{
${ }^{6} \mathrm{R}$. Barthes, Investigaciones retóricas. I. La antigua retórica, Barcelona, Eds. Buenos Aires, 1982, pp. 12-14.

7 A. Reyes, "La antigua retórica", en Obras completas, vol. XIII, México, FCE, 1961, pp. 349 ss.
} 

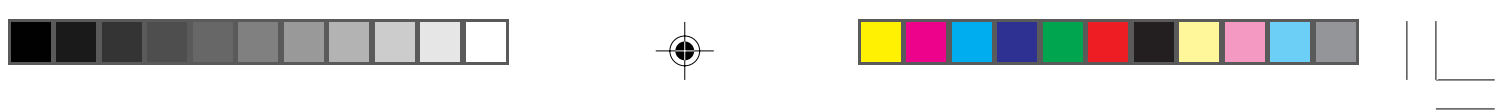

RETÓRICA Y HERMENÉUTICA / Noua tellus, 25•1, 2007, pp. 217-234

logo no siempre es desapasionado y cerebral, y por ello tiene que ayudarse del ornato para la persuasión; tiene que acudir a los resortes pasionales para llegar a la convicción. Va más allá del lógos apophantikós, que corresponde a la sintaxis y a la semántica, y avanza hasta el lógos semantikós, que más bien diríamos ahora que es la parte de la pragmática y la hermenéutica, porque va más a la comprensión que a la explicación, $\mathrm{y}$, aunque es intelectiva, no descuida lo volitivo, y atiende más a lo peculiar que a lo universal del hombre.

\section{Función de la retórica}

En el libro I de la Retórica, Aristóteles dedica los capítulos 1 y 2 a definir la naturaleza de la retórica. La observa como una parte de la lógica o teoría de la argumentación. Resalta más la parte intelectiva que la volitiva del hombre, da más cabida al concepto que al afecto. En esa orientación al bien común de la polis, la retórica argumenta, es decir, alude al intelecto/razón, y el mover los afectos es algo derivado. Por eso la retórica, para Aristóteles, se relaciona con la dialéctica, ${ }^{8}$ ambas pertenecen a la tópica, esto es, hay tópicos dialécticos y tópicos retóricos; la dialéctica procura la verdad plausible o probable (a diferencia de la lógica analítica, que asegura lo apodíctico o necesario), y la retórica se contenta con lo verosímil.

La lógica estudia qué es el silogismo, no solamente el silogismo completo, de los Analíticos Primeros, sino también el entimema, que es el silogismo trunco o abreviado, ${ }^{9}$ y que, en el caso de la dialéctica o tópica, llega a la verdad probable, y en el caso de la retórica sólo alcanza lo verosímil. ${ }^{10}$ Por eso

\footnotetext{
${ }^{8}$ Rhet., I, 1, 1354a 1-6, y 1355a 10.

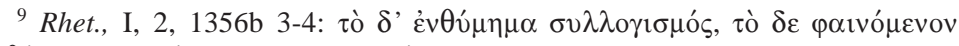

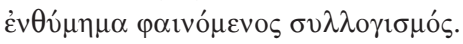

${ }^{10}$ Rhet., I, 1, 1355a 5-23.
} 


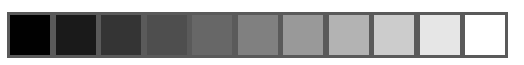

la retórica se distingue de la lógica, como la de los Analíticos, porque no aspira a lo verdadero, sino a lo verosímil. Eso la acerca a la dialéctica, como la de los Tópicos, que trata de una verdad más modesta: la probable o plausible (no la necesaria o apodíctica). También la retórica se distingue por el uso del silogismo abreviado, el entimema, lo cual se debe al curso más rápido de la oratoria, a diferencia de la discusión dialéctica. Ya en eso hay discrepancias entre la retórica y la dialéctica; pero, además, difieren porque en la dialéctica no se mueven las pasiones, cosa que en la retórica es fundamental.

La retórica trata de lo verosímil porque lo evidente no admite discusión, y lo probable no admite persuasión; en cambio, versa sobre lo discutible que puede alcanzar verosimilitud y aporta, al modo como los tópicos de la dialéctica, motivos de credibilidad a partir de nociones comúnmente aceptadas. Se parece a la phrónesis o prudencia, en que delibera para encontrar y ofrecer los medios para llegar al fin de la persuasión, que es hacer que algo sea creíble o verosímil. ${ }^{11}$

La retórica puede persuadir acerca de cualquier cosa. Incluso acerca de cosas probables o aún evidentes, aunque no las demuestra. Por eso lo probable también puede ser asumido por la argumentación retórica; e incluso lo apodíctico o evidente, ya que, cuando alguien lo niega o no quiere aceptarlo, el único recurso argumentativo que nos queda es retórico. $\mathrm{O}$ puede pasar que no sean primeros principios los que se ponen en duda, sino cosas verdaderas pero sin evidencia inmediata, y resultan verdades apodícticas que son reafirmadas o confirmadas retóricamente. Por tal razón lo verosímil abarca lo verdadero, tanto apodíctico como tópico, y los tres entran en la retórica.

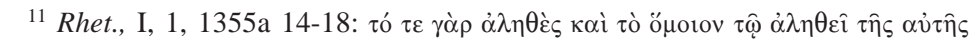

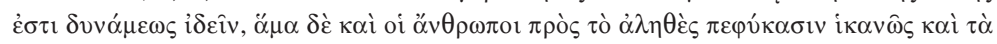

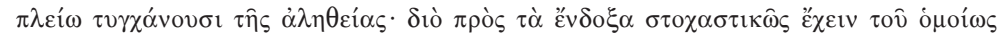

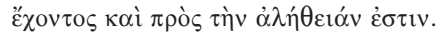



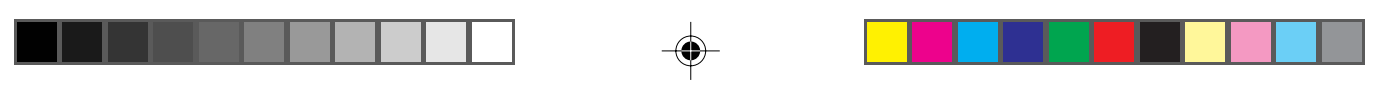

RETÓRICA Y HERMENÉUTICA / Noua tellus, 25•1, 2007, pp. 217-234

Además de distinguirse de la analítica y la tópica, la retórica debe diferenciarse de la sofística, pues esta última presenta lo falso como verdadero y como verosímil. Y no sólo eso, sino que se añade que lo hace contenciosamente y con engaño. Es decir, no se queda en lo falso o inválido, como el paralogismo, sino que el sofisma o falacia es lo falso que parece verdadero (por eso es doblemente peligroso).

Es el mismo Aristóteles quien dice que los argumentos retóricos pueden aludir al intelecto o a la voluntad, e incluso pueden ser cosas ajenas al arte retórica. Por eso divide tales argumentos retóricos en extrínsecos al arte (písteis átechnoi, los que le preexisten, como los testigos, la tortura, etcétera) e intrínsecos al arte (písteis éntechnoi, los que van incrementando al paso que evoluciona esta disciplina). ${ }^{12}$

Hay, pues, argumentos intrínsecos o intraartísticos y otros que son extrínsecos. Los intrínsecos son válidos, y son de tres clases: (i) unos se basan en el carácter del que habla, (ii) otros se apoyan en el estado de ánimo que tienden a provocar en el oyente, y (iii) otros se centran en el discurso, de acuerdo con lo que significa o parece significar. Los argumentos (i) y (ii) son psicagógicos, esto es, se fundamentan en aspectos psicológicos, unos en el carácter del que habla, aprovechando la autoridad que le confieren sus buenas costumbres, la cual inclina el ánimo de los oyentes a darle crédito; y los que se fundamentan en el ánimo de los oyentes son semejantes: el grado de concesión al que llegan los oyentes predispuestos, ánimo que puede causarse o cambiarse (y en ello reside la psicagogía). Pero los del tipo (iii) son argumentos más propios de la lógica y la teoría de la argumentación, pues se basan en el mismo discurso, por cuanto que muestran lo verdadero o lo verosímil de

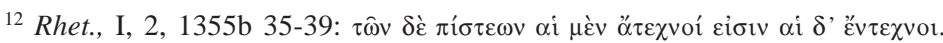

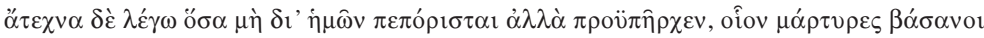

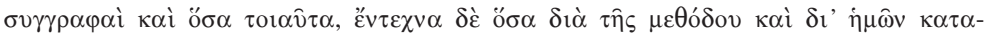

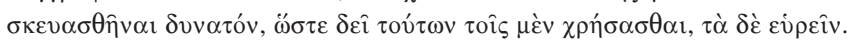




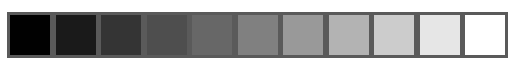

226

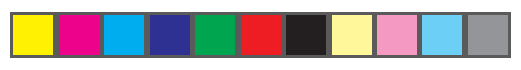

BEUCHOT / Noua tellus, 25•1, 2007, pp. 217-234

acuerdo con lo que resulta persuasivo en cada caso. En cuanto estudia las costumbres y los caracteres, dice Aristóteles que la retórica es aledaña a la política; mas nunca pierde su carácter racional, o lógico. ${ }^{13}$ En ella confluyen la lógica y la psicología al servicio de la política.

La pragmática y la hermenéutica se hacen presentes en la retórica porque ella no aporta razones tan claras y contundentes, sino razones más necesitadas de comprensión o interpretación, y más débiles. Dichas razones tienen dos clases prin-

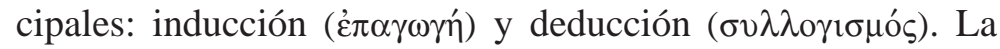
inducción abreviada es el paradigma o ejemplo, y la deducción abreviada es el entimema. ${ }^{14} \mathrm{Y}$ estos dos últimos son los más propios de la retórica.

Los discursos que proceden por entimemas son mejores que aquellos que proceden por paradigmas, pero ambos son creíbles. Aunque la retórica admite premisas necesarias, son pocas, y las más abundantes son las contingentes. Es la contingencia que los escolásticos llamaron ut in pluribus o frecuente, que es la verosímil (contrapuesta a la contingencia ut in paucioribus o rara, la cual no sirve para argumentar). Además de usar argumentos, el retórico puede utilizar indicios. Con todo, son más eficaces los rhetores que usan argumentos. Y estos argumentos se apoyan en los tópicos, como el del más y el menos ("El que puede lo más puede lo menos", por ejemplo, "Si un capitán puede mandar esto o aquello, mucho más un general"). Los tópicos son principios de la argumentación, ${ }^{15}$

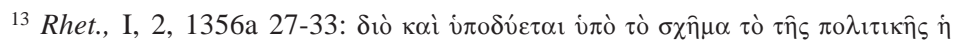

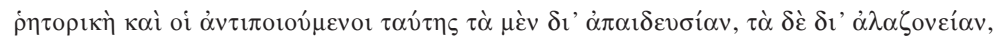

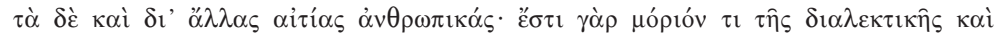

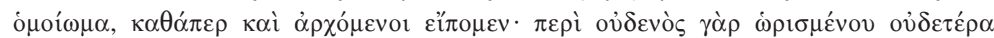

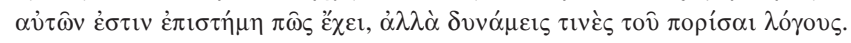

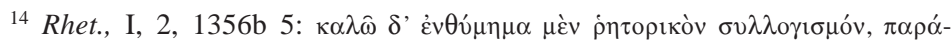

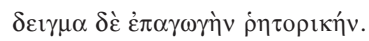

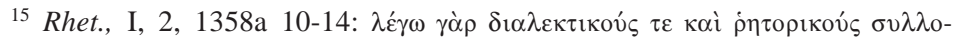

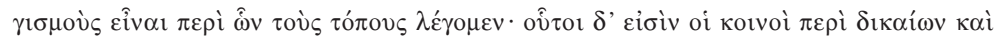



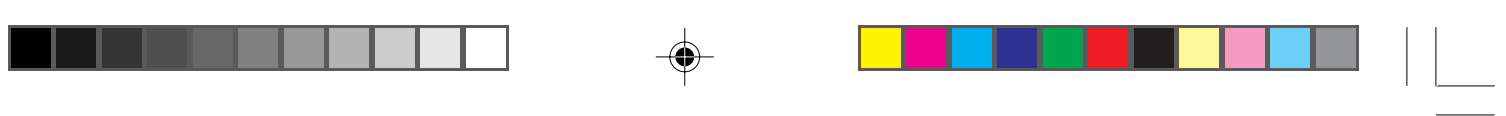

RETÓRICA Y HERMENÉUTICA / Noua tellus, 25•1, 2007, pp. 217-234

que en la lógica actual se han interpretado como reglas de inferencia o como esquemas de argumentos. En realidad son nociones comunes o juicios generalmente aceptados, los cuales marcan un paso consecuencial que se establece como regla de inferencia; pero tienen que ser compartidos por la comunidad epistémica, esto es, por los dialogantes; por eso son lugares comunes. Esta interacción es todo un acontecimiento semiótico en el que se requiere la atención a los usuarios, por lo que pertenece a la pragmática, la cual coincide con la hermenéutica.

\section{Retórica, pragmática y hermenéutica}

En efecto, la pragmática y la retórica coinciden, pues no se quedan en el significado sintáctico-semántico, sino que van al significado del hablante, toman en cuenta a los usuarios, su intencionalidad (es el significado pragmático). Además, la retórica no se reducía a la mera psicagogía; era una teoría de la argumentación. Se colocaba entre las ramas de la lógica: la analítica y la tópica, y se unía a la poética, la otra disciplina de lo verosímil. Podrá resultar difícil de entender que la retórica y la poética eran partes de la lógica, del Órganon, pero, así como la lógica argumenta en pro de la verdad, así también la retórica argumenta a favor de lo verosímil, y la poética tenía ciertos tópicos que daban verosimilitud a las composiciones poéticas. A la retórica, pues, se le exige la verosimilitud; no se le puede exigir la verdad, ni siquiera la probable, mucho menos la necesaria. Por ser verosímil, se distingue de la lógica analítica o apodíctica, de verdad necesaria, y de la lógica tópica o dialéctica, de verdad probable o plausible; pero sólo se distingue de ellas en las premisas y la conclusión, no en la fuerza

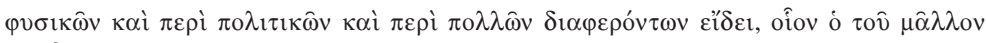

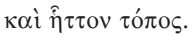




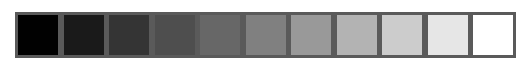

228

BEUCHOT / Noua tellus, 25.1, 2007, pp. 217-234

inferencial, que es la misma. Tiene igual validez lógica, pero difiere en los contenidos, que son sólo verosímiles; y, si son tales las premisas, también ha de serlo la conclusión.

Pero la retórica es, en el pensamiento de Aristóteles, la argumentación que va hacia el hombre íntegro, intelecto y afecto; no alude sólo a su parte racional, sino también a la emocional. Esto no lo hace la lógica: ni la tópica ni, mucho menos, la analítica. Hablando desde la semiótica, la retórica entra en el terreno de la pragmática, en el que no bastan la sintaxis y la semántica, más neutras, sino que va a consideraciones más psicológicas, como el manejo de las pasiones. Es más performativa, y en eso coincide con la hermenéutica. Además, la retórica era, antiguamente, el equivalente de la hermenéutica, porque, junto con la poética, estudiaba los tropos, esto es, los recursos comunicativos (o expresivos) en el discurso. Ellos servían para encodificar o transmitir, pero igualmente para decodificar o recibir. Es decir, lo que servía para escribir servía para leer, y, de esta manera, las retóricas eran uno de los lugares naturales de la hermenéutica. Por eso en la retórica de Aristóteles hemos encontrado los rasgos principales de su hermenéutica. Pero, también, hallamos en el estagirita un elemento que puede caracterizar adecuadamente su concepción retórico-hermenéutica: el concepto de analogía.

\section{La analogía en la retórica y en la hermenéutica}

Aristóteles habla de tres tipos de predicación o de significado. (i) Uno es el sinónimo, es decir, unívoco (completamente igual para los significados y los sujetos de atribución); otro es la equivocidad u homonimia, que es la diversidad de significado y de predicación, y ésta se divide en dos: (ii) equívoco casual, completamente irreductible a la univocidad, y (iii) equívoco deliberado, que es la analogía, también irreductible a la uni- 

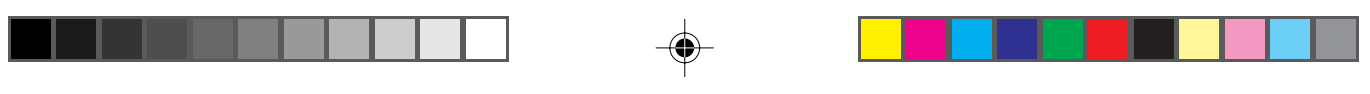

RETÓRICA Y HERMENÉUTICA / Noua tellus, 25•1, 2007, pp. 217-234

vocidad, pero lo suficientemente claro como para brindar un conocimiento adecuado. ${ }^{16}$

Aristóteles usa muy poco la palabra "analogía", pero siempre que la usa la entiende como proporción, como proporcionalidad. Es la proporción de los pitagóricos: a:b::c:d. Pero también usa otra expresión que corresponde a la analogía, y

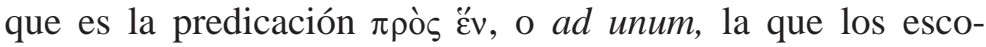
lásticos llamaban, tras Cayetano, "de atribución”. Esta última es de proporción simple: a:b, a:c, a:d... Por ejemplo, "sano" se atribuye al organismo, al medicamento, al alimento, al clima, hasta a la orina, pero sólo al primero de manera propia, por lo que es el analogado principal, y los demás los analogados secundarios. ${ }^{17}$

Esta analogía de atribución fue después dividida en intrínseca y extrínseca. La primera implica una atribución propia, la otra no. La analogía de proporcionalidad también fue dividida en dos: una propia y otra impropia o metafórica. ${ }^{18}$ En el tomismo se privilegió la analogía de proporcionalidad, como en Cayetano ${ }^{19}$ y Juan de Santo Tomás; la de atribución fue privilegiada por Suárez. Más modernamente, Owens ${ }^{20}$ (1951) y Aubenque ${ }^{21}$ privilegian la predicación $\pi \rho \grave{\varsigma}$ ह̌v, pero la ven como un equívoco. Para el primero, eso significa que la metafísica es teología; mientras, para el segundo, que no puede ser ciencia en sentido estricto.

Se trata de la equivocidad $\pi \rho \grave{s} \varsigma \check{\varepsilon} v$ (Owens), i. e., la de atribución, y no de la equivocidad $\kappa \alpha \tau^{\prime} \dot{\alpha}^{2} \alpha \lambda \lambda_{0} \gamma_{i} \alpha v$, la de pro-

\footnotetext{
${ }^{16}$ Cat., 1, 1a 1-12.

${ }^{17}$ Cat., 5, 2b 5-6; Eth. Nic., V, 3, 1131a 31- b 4.

${ }^{18}$ Poet., 21, 1457b 16-18.

19 Tomás de Vío Cayetano, De nominum analogia, intr., trad. y notas de Vicente Igual, Barcelona, PPU, 1989.

${ }^{20}$ J. Owens, The Doctrine of Being in the Aristotelian Metaphysics, Toronto, Pontificial Institute of Mediaeval Studies, 1963.

${ }^{21} \mathrm{P}$. Aubenque, Le problème de l'être chez Aristote. Essai sur la problématique aristotelicienne, Paris, Presses Universitaires de France, 1962.
} 


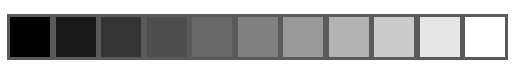

230

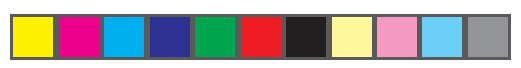

BEUCHOT / Noua tellus, 25•1, 2007, pp. 217-234

porcionalidad. Owens, con Suárez, privilegia la de atribución, y sólo justifica la filosofía primera como teología; en cambio, Suárez la ve como intrínseca (Owens sólo como extrínseca); ${ }^{22}$ por eso Suárez puede justificar la ontología o metafísica. Aubenque ni siquiera deja cientificidad a la metafísica, por ponerle exigencias demasiado formalistas o logicistas. ${ }^{23}$ Esto le pasa a Aubenque debido a un ideal de univocidad que ha tomado — según Muralt- de la fenomenología. ${ }^{24}$

Sin embargo, la atribución tiene como base la proporcionalidad. Esta última es como una meta-analogía, que está presente en toda analogía, incluso la de atribución o de proporción simple. El propio Aristóteles, en su doctrina de la analogía, re-

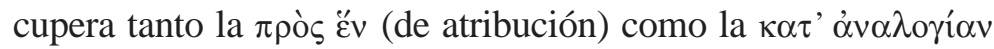
(de proporcionalidad) y las integra en una sola. ${ }^{25}$

Pues bien, la analogía es, en Aristóteles, el reconocimiento de la polisemia de ciertos términos, que son los principales en la filosofía. Tal es el caso del ente, cosa que estudió acuciosamente Brentano, en su trabajo Sobre el múltiple sentido del ser en Aristóteles, ${ }^{26}$ que Heidegger leyó de joven y le marcó toda su filosofía (él se debatió entre la analogía y la univocidad en toda su reflexión, optando en definitiva por esta última). Es la conciencia de que la realidad es compleja pero también de que podemos estudiarla y conocerla; ciertamente no de manera exhaustiva, pero sí lo suficiente como para poder manejarla. Hay, según decía Peirce, una ambigüedad radical en la realidad, y le vamos arrancando la claridad, sin llegar nunca a lo unívoco. Por lo menos nos quedamos en una

\footnotetext{
22 J. Owens, op. cit., pp. 124-125.

${ }^{23}$ P. Aubenque, op. cit., pp. 235 ss.

${ }^{24}$ A. de Muralt, Comment dire l'être? L'invention du discours métaphysique chez Aristote, Paris, Vrin, 1985, pp. 29-36.

${ }^{25}$ Met., V, 6, 1016b 31-35.

${ }^{26}$ Brentano, Von der mannigfachen Bedeutung des Seienden nach Aristoteles, Hildesheim, G. Olms, 1960.
} 

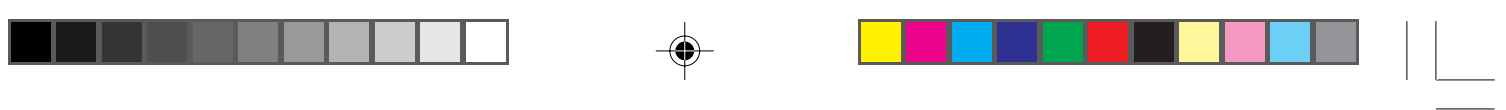

RETÓRICA Y HERMENÉUTICA / Noua tellus, 25•1, 2007, pp. 217-234

ambigüedad sistemática, en terminología de Russell, que es la que corresponde al conocimiento analógico.

La retórica (al igual que la poética) es eminentemente hermenéutica porque estudia los tropos o figuras del discurso, principalmente la metáfora y la metonimia. Y la analogía contiene eso, ya que tiene un polo metonímico, el cual corresponde a la analogía de atribución intrínseca y a la de proporcionalidad propia, y tiene un polo metafórico, que corresponde a la analogía de atribución extrínseca y a la de proporcionalidad impropia o metafórica. Según Jakobson, la metonimia rige la prosa y la metáfora la poesía. ${ }^{27}$ Es decir, metonimia y metáfora son los dos pilares del discurso humano, pues la metonimia se da en el discurso científico y la metáfora en el lírico. Y ambos polos se juntan en la analogía, son polos de la analogía misma.

De esta manera, la analogía (pitagórica, potenciada por Platón y Aristóteles) tiene una fuerza comprensiva, desde lo metonímico hasta lo metafórico, que resulta muy útil para la interpretación. Da la posibilidad de encodificar retóricamente y decodificar hermenéuticamente una amplia gama de significados, esto es, de textos. Ayuda a lograr una interpretación diferenciada, que escapa de la pretensión de univocidad (que se alcanza en pocos ámbitos), sin caer en la trampa de la equivocidad (que hunde en el caos). Es, en todo caso, una apertura, pero no indiferenciada, no absoluta, sino limitada, acotada, diferenciada. Y con ello nos basta para alcanzar una comprensión suficiente. Asimismo, permite entender, por proporción con lo ya conocido, cosas desconocidas, significados extraños o extranjeros. Y, además, nos permite encontrar un analogado principal entre las interpretaciones que tenemos de un texto, y con ello jerarquizar las demás conforme al grado de aproximación a la verdad textual que alcancen.

\footnotetext{
${ }^{27}$ R, Jakobson, "Lingüística y poética”, en sus Ensayos de lingüística general, México, Origen-Planeta, 1986, pp. 389.
} 


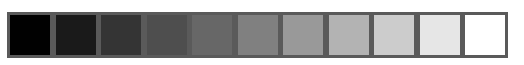

232

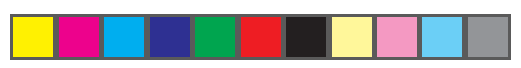

BEUCHOT / Noua tellus, 25·1, 2007, pp. 217-234

\section{La analogía como clave hermenéutica}

La analogía, pues, tiene en Aristóteles el sentido de polisemia o multivocidad. En el libro V de la Metafísica, de la mayoría de los conceptos filosóficos (el ser, el uno, el bien, la causa, etcétera) asegura que cada uno se dice de muchas maneras ( $\pi \mathrm{o} \lambda \lambda \alpha \chi \omega \varsigma \varsigma \lambda \varepsilon ́ \gamma \varepsilon \tau \alpha \mathrm{l}) \mathrm{y}$, sobre todo, lo dice del ser. ${ }^{28}$ Pero también dice que esa polisemia no es mera homonimia o equivocidad, sino una predicación o significación ordenada, tomando algún término como principal, y los demás se dicen por relación con

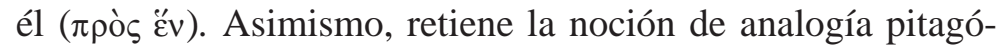
rica como proporción, según se ve en la ética y en la política, al hablar de la justicia, la cual, en su carácter de conmutativa, observa una proporción aritmética y, en su carácter de distributiva, una proporción geométrica.

Con esto entendemos que la analogía, además de implicar polisemia, implica una significación proporcionada, de modo que no es mera equivocidad, sino que guarda una cierta unidad proporcional. Asimismo, implica que a veces se da una polisemia ordenada, jerarquizada, con un orden de atribución, en la que un significado se atribuye a los distintos conceptos involucrados de manera gradual, a uno de manera más propia y a otros de manera menos propia, esto es, según un analogado principal y otros analogados secundarios, lo cual da la posibilidad de interpretar no de manera unívoca, sino con cierta apertura, pero sin caer en la equivocidad.

Aristóteles pone buen cuidado en señalar que la analogía no se reduce a la mera homonimia o equivocidad, o por lo menos se queda en una homonimia o equivocidad deliberada, sistemática, controlada. La idea del estagirita parece ser que la analogía es un tipo de equivocidad, pero no la equivocidad casual, que es

\footnotetext{
${ }^{28}$ Como lo había enunciado ya en Met., IV, 2, 1003a 34 ss.
} 

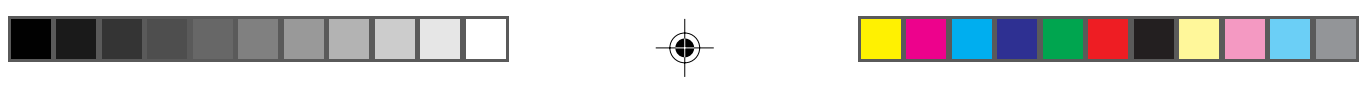

RETÓRICA Y HERMENÉUTICA / Noua tellus, 25•1, 2007, pp. 217-234

irreductible, sino una equivocidad deliberada y que se puede salvar del caos, aunque nunca se llegue en ella a la univocidad. Esto, verdaderamente, abre mucho la riqueza de la hermenéutica aristotélica que, al evitar la univocidad de los significados rígidos, no se desliza hacia la equivocidad de los significados caóticos, sino que se mantiene en una interpretación mesurada, equilibrada, tal como se requiere en la phrónesis o prudencia aristotélica, que Gadamer ha puesto como esquema y modelo de la hermenéutica, cuando dice:

La virtud aristotélica de la racionalidad, la phrónesis, resulta ser al final la virtud hermenéutica fundamental. A mí me sirvió de modelo para mi propia línea argumentativa. De ese modo la hermenéutica, esa teoría de la aplicación, es decir, de la conjugación de lo general y lo individual se convirtió para mí en la tarea filosófica central. ${ }^{29}$

\section{Conclusión}

De esta manera vemos cómo la hermenéutica de Aristóteles está vinculada a su retórica, ya que en ella se encuentra una teoría de los tropos, que son los que ofrecen dificultad para ser interpretados. Y, aunque la retórica los enseña para ser usados en la prolación de piezas oratorias, igualmente se pueden usar para leer y comprender dichas piezas, que, junto con las poéticas, son las más complejas. Podemos decir que, aunque no sea conscientemente, subyace la idea de que lo que sirve para encodificar sirve para decodificar, o lo que sirve para escribir sirve para leer, o lo que sirve para emitir (oratoria) sirve para recibir (hermenéutica).

Además, un punto nuclear de la hermenéutica aristotélica se encuentra en su doctrina de la analogía, esto es, de la polisemia

\footnotetext{
${ }^{29}$ H.-G. Gadamer, "Problemas de la razón práctica", en Verdad y método II, Salamanca, Sígueme, 1994, p. 317.
} 


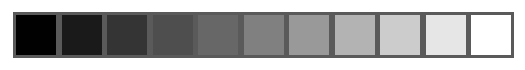

234

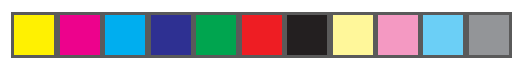

BEUCHOT / Noua tellus, 25.1, 2007, pp. 217-234

proporcional y ordenada, que escapa de la mera univocidad y de la mera equivocidad, y es la que más frecuentemente logramos obtener. Se trata, pues, de una hermenéutica analógica. En ella no se alcanza la claridad del significado unívoco, pero tampoco se cae en la oscuridad del significado equívoco; se alcanza un significado no tan claro como el unívoco, pero tampoco tan oscuro como el equívoco; dicho en otras palabras, el conocimiento analógico $-\mathrm{y}$, dentro de él, la interpretación analógica - nos da una comprensión limitada pero suficiente. 